CHRONIC OBSTRUCTIVE PULMONARY DISEASE

\title{
Increased risk of chronic obstructive pulmonary diseases in coke oven workers: interaction between occupational exposure and smoking
}

\author{
Y Hu, B Chen, Z Yin, L Jia, Y Zhou, T Jin
}

See end of article for authors' affiliations

Correspondence to: Dr T Jin, Department of Environmental and Occupational Health, Fudan University,

Shanghai, 200032, P R

China; tyjin@shmu.edu.cn

Received 16 August 2005 Accepted 22 January 2006 Published Online First 7 February 2006
Background: Coke oven workers are regularly exposed to coke oven emissions (COE) and may be at risk of developing lung diseases. There is limited evidence for the link between exposure to COE and chronic obstructive pulmonary diseases (COPD). The aim of this study was to explore the dose-response relationship between COE exposure and COPD and to assess the interaction with cigarette smoking.

Methods: Seven hundred and twelve coke oven workers and 211 controls were investigated in southern China. Benzene soluble fraction (BSF) concentrations as a surrogate of COE were measured in representative personal samples and the individual cumulative COE exposure level was quantitatively estimated. Detailed information on smoking habits and respiratory symptoms was collected and spirometric tests were performed.

Results: The mean BSF levels at the top of two coking plants were 743.8 and $190.5 \mu \mathrm{g} / \mathrm{m}^{3}$, respectively, which exceed the OSHA standard $\left(150 \mu \mathrm{g} / \mathrm{m}^{3}\right)$. After adjusting for cigarette smoking and other risk factors, there was a significant dose-dependent reduction in lung function and increased risks of chronic cough/phlegm and COPD in coke oven workers. The odds ratio for COPD was 5.80 (95\% confidence interval 3.13 to 10.76) for high level cumulative COE exposure ( $\geqslant 1714.0 \mu \mathrm{g} / \mathrm{m}^{3}$-years) compared with controls. The interaction between COE exposure and smoking in COPD was significant. The risk of COPD in those with the highest cumulative exposure to COE and cigarette smoking was 58-fold compared with non-smokers not exposed to COE.

Conclusion: Long term exposure to COE increases the risk of an interaction between COPD and cigarette smoking.
$\mathrm{C}$ hronic obstructive pulmonary disease (COPD) is a major cause of chronic morbidity and mortality throughout the world, and further increases in the prevalence and mortality of the disease can be predicted in the coming decades. ${ }^{12}$ Although cigarette smoking is clearly the major risk factor for COPD, there is an increasing recognition that occupational exposures such as in coal miners, hard rock miners, tunnel workers, and concrete manufacturing workers increase the likelihood of COPD. ${ }^{3-6}$ It is estimated from a population based investigation that one in five cases of COPD may be attributable to occupational exposure. $^{7}$ Considering the high prevalence of COPD and preventability of occupational related disease, studies on the effects of specific occupational exposure could have a major public health impact.

Coke is produced by blending and heating suitable grades of coals to $1000-1400^{\circ} \mathrm{C}$ in the absence of oxygen. Tars and light oils are distilled out of the coal and gases are generated during this process. Its manufacture is one of the most polluted industrial processes. It is estimated that there are more than 1900 coking plants nationwide with a capacity of 180 million tonnes and more than 300000 coke oven workers in China. Coking workers are regularly exposed to coke oven emissions (COE), which are mainly comprised of a variety of volatile organic compounds and particulates, especially polycyclic aromatic hydrocarbons (PAHs). ${ }^{8}$ Such emissions have been found to have harmful health effects on workers. Epidemiological studies showed workers with long term exposure to COE had a significantly higher risk of lung cancer. ${ }^{9} 10$

To date there has been only limited evidence for the link between exposure to $\mathrm{COE}$ and COPD, although some industry based studies showed respiratory impairment and reduced lung function in coke oven workers. ${ }^{11-13}$ Previous studies have not assessed individual exposures in coke oven workers, so a quantitative dose-response relationship between $\mathrm{COE}$ exposure levels and COPD has not been undertaken.

Because of the large number of constituent chemical agents, the US Occupational Safety and Health Administration (OSHA) chose to use the benzene soluble fraction (BSF) of total particulates to be representative of COE and set a permissible exposure limit (PEL; 8 hour time weighted average) of $150 \mu \mathrm{g} / \mathrm{m}^{3} .{ }^{14}$ BSF contains mainly PAHs and has been an accepted measure of exposure to COE throughout the world. In this study, individual air BSF exposure as a surrogate of COE was measured. Information on tobacco consumption and cumulative exposure for each coke oven worker was also collected to explore the doseresponse relationship between COE exposure and COPD and to assess the interaction with cigarette smoking.

\section{METHODS}

\section{Subjects}

Sample size for this study was determined by estimating the difference between population proportions of COPD with specified absolute precision. We assumed the prevalence of COPD in association with COE exposure was about $15 \%$, compared with background rates of about $5 \%$ in the absence

Abbreviations: $B S F$, benzene soluble fraction; $\mathrm{COE}$, coke oven emissions; COPD, chronic obstructive pulmonary disease; $\mathrm{FEV}_{1}$, forced expiratory volume in 1 second; $\mathrm{FEF}_{25-75 \%}$, forced expired flow from $25 \%$ to $75 \%$ of FVC; FVC, forced vital capacity; PAH, polycyclic aromatic hydrocarbon 
of exposure. To detect this difference to within 5\% percentage points of the true value with $90 \%$ confidence would require 195 persons per group..$^{15}$ (The higher confidence level was considered necessary because multiple comparisons would be made of the risks.) Our sample design included three levels of COE exposure so a total of at least 600 coke oven workers needed to be included.

The study was conducted at two coking plants (exposure group) and an institute of equipment calibration (control group) in south east China from May to December 2003. The coking plants had been in operation since the 1970s and approximately 300 and 500 workers, respectively, were exposed to COE in coking plants I and II during the study period. There were four and six coke ovens at plants I and II, respectively. Coke production in the two plants was continuous (24 hours/day), and each work cycle consisted of 8 days and three different shifts: two consecutive morning shifts and two consecutive afternoon shifts in the first 4 days, 5th day off duty, two consecutive night shifts, and then rest on the 8th day. Coke oven workers served on one shift for 6 hours. The institute of equipment calibration had about 220 employees and was about $2 \mathrm{~km}$ and $300 \mathrm{~km}$ away from coke plants I and II, respectively. None of the controls had any direct or indirect work related exposure to $\mathrm{COE}$ or other toxins.

A detailed questionnaire was completed by the study participants. Interviews were conducted by three trained interviewers using a structured questionnaire. Each was asked to indicate age, smoking, alcohol consumption, protective mask use, viral infections, family history of diseases, histories of occupations, and diseases. Questions about smoking included the age of onset of regular smoking, the average number of cigarettes smoked during different time periods, duration of smoking, and details on periods of smoking cessation. Cigarette-years were calculated as the product of the number of years an individual smoked and the average number of cigarettes smoked per day. Respiratory symptoms including cough and phlegm were assessed for the year before the investigation. Chronic cough or phlegm was defined as cough or phlegm production a minimum of 3 months a year during the course of 1 year. None of the participants in the study had a history of thoracic or abdominal surgery, tuberculosis treatment, or exposure to any toxins before they were employed. They should have been employed for at least 1 year at the beginning of the investigation ( $\mathrm{n}=299,492$, and 222 subjects in coking plant I, coking plant II, and controls, respectively). A total of 79 coke oven workers $(10.0 \%)$ and 11 controls $(4.9 \%)$ refused to participate. After exclusion of these subjects, the final study population consisted of 712 coke oven workers and 211 controls

The study was undertaken with the permission of the local authority and the ethics committee of the School of Public Health, Fudan University. Informed consent was obtained from each participating individual.

\section{Personal BSF sampling and determination}

Personal air sampling based on US OSHA guidelines was carried out during the study period. ${ }^{16}$ Coke oven workers were from the bottom, middle and top of the oven. Twenty personal breathing zone air samples were randomly obtained from each of these positions in the two coking plants using a battery operated personal portable air sampling pump (model MG-5P, USA) for four consecutive days in May and December 2003. A two piece sampling cassette with $37 \mathrm{~mm}$ glass fibre filters was attached to the lapel of each worker. The sampling apparatus was calibrated by Gilibrator 2 (USA) before sampling. Subjects were sampled for 6 hours during one complete working day. All of samples were analysed for
BSF using OSHA analytical methods. ${ }^{16}$ Fifteen randomly selected personal samples from the control group were also collected during five consecutive days in May and December 2003 and measured as described above.

\section{Estimation of cumulative exposure to $\mathrm{COE}$}

There had been no operational improvement to the coke ovens at the two coking plants since 1975. About one million tons of coke are produced annually at each coking plant. Coke oven workers do not always wear a mask when working mainly because there is no flexible ventilation. They changed job positions at the coke ovens during their employment, so a cumulative level of COE exposure was estimated by summing the product of the mean exposure level for each working position (bottom, middle and top of the coke oven) and by the number of years this activity was performed according to company records. Based on the distribution of estimated cumulative COE exposure, three tertiles of exposure were defined: $\quad<630.0 \mu \mathrm{g} / \mathrm{m}^{3}$-years (low exposure), 630.0$1713.0 \mu \mathrm{g} / \mathrm{m}^{3}$-years (moderate exposure), and $\geqslant 1714.0 \mu \mathrm{g} /$ $\mathrm{m}^{3}$-years (high exposure).

\section{Lung function measurement and COPD screening}

Lung function was measured in the sitting position with a spirometer (model SIROVIT SP-10) operated by the same trained technician. The measurements were performed in accordance with the guidelines recommended by the American Thoracic Society. ${ }^{17}$ Room and spirometer temperature and barometric pressure were recorded. Height was measured without shoes in the standing position with nose clips. Each subject performed at least three preferably identical forced vital capacity (FVC) curves-that is, within a variation of $50 \mathrm{ml}$ or a maximum of $2 \%$. The best forced expiratory volume in 1 second $\left(\mathrm{FEV}_{1}\right)$ values was selected for statistical analysis. Recorded indices were FVC, $\mathrm{FEV}_{1}, \mathrm{FEV}_{1} /$ FVC, and forced expired flow from $25 \%$ to $75 \%$ of FVC $\left(\mathrm{FEF}_{25-75}\right)$. The lung function variables were expressed in absolute values and as percentage of predicted. A reference value for $\mathrm{FEV}_{1}$ in the investigated areas had not previously been established, so the predicted value of $\mathrm{FEV}_{1}$ for this study was calculated by the following reference regressions established from lung function measurements of 169 healthy non-smokers randomly selected from the same study areas during the study period (98 men of mean (SD) age 30.1 (8.6) years, height $169.7(5.0) \mathrm{cm}$ and 71 women of mean (SD) age $26.0(4.6)$ years, height $158.2(4.3) \mathrm{cm})$.

Men: $\mathrm{FEV}_{1}=-2.181+0.04292 \times \mathrm{H}-0.0215 \times \mathrm{A}$

Women: $\mathrm{FEV}_{1}=-2.813+0.04315 \times \mathrm{H}-0.0274 \times \mathrm{A}$ where $\mathrm{H}=$ height in $\mathrm{cm}$ and $\mathrm{A}=$ age in years.

COPD and severity of the disease were defined according to GOLD criteria (mild: $\mathrm{FEV}_{1} / \mathrm{FVC}<70 \%$ and $\mathrm{FEV}_{1} \geqslant 80 \%$ predicted with or without chronic symptoms; moderate: $\mathrm{FEV}_{1} / \mathrm{FVC}<70 \%$ and $50 \% \leqslant \mathrm{FEV}_{1}<80 \%$ predicted with and without chronic symptoms; severe: $\mathrm{FEV}_{\mathrm{l}} / \mathrm{FVC}<70 \%$, $30 \leqslant \mathrm{FEV}_{1}<50 \%$ predicted with or without chronic symptoms; very severe: $\mathrm{FEV}_{1} / \mathrm{FVC}<70 \%, \mathrm{FEV}_{1}<30 \%$ predicted). ${ }^{18}$

\section{Statistical analysis}

Statistical analysis was conducted using SPSS 10.0. Demographic data were summarised for each group using mean and standard deviation for continuous data and numbers (\%) for categorical data. The mean lung function indices adjusted for sex, age and smoking by general linear model were presented. Corresponding 95\% confidence intervals (CI) were also calculated. Unconditional logistic regression was used to analyse the risk of respiratory symptoms or COPD in relation to cumulative COE exposure and smoking (cigarette-years) and with adjustments made for sex, age, height, and cigarette-years of smoking (when analysing the 
Table 1 Basic characteristics of exposure groups and control group

\begin{tabular}{|c|c|c|c|c|}
\hline & $\begin{array}{l}\text { Control group } \\
(n=211)\end{array}$ & $\begin{array}{l}\text { Low exposure } \\
(n=238)\end{array}$ & $\begin{array}{l}\text { Moderate exposure } \\
(n=237)\end{array}$ & $\begin{array}{l}\text { High exposure } \\
(n=237)\end{array}$ \\
\hline \multicolumn{5}{|l|}{ Sex $\ddagger$} \\
\hline Men & $192(91.0)$ & $215(90.3)$ & $234(98.7)^{\star \star}$ & $223(94.1)$ \\
\hline Women & $19(9.0)$ & $23(9.7)$ & $3(1.3)$ & $14(5.9)$ \\
\hline Age (years) & $35.7(8.0)$ & $34.6(8.2)$ & $37.9(8.0)^{*}$ & $35.3(7.2)$ \\
\hline \multicolumn{5}{|l|}{ Age group (year) $\ddagger$} \\
\hline$<30$ & $53(25.1)$ & 79 (33.2) & $41(17.3)$ & $51(21.5)$ \\
\hline $30-34$ & $49(23.2)$ & 45 (18.9) & $44(18.6)$ & $74(31.2)$ \\
\hline $35-39$ & $43(20.4)$ & 38 (16.0) & 46 (19.4) & 58 (24.5) \\
\hline $40+$ & $66(31.3)$ & 76 (31.9) & $106(44.7)^{*}$ & $54(22.8)$ \\
\hline Height $(\mathrm{cm}) \top$ & $168.6(5.4)$ & $167.8(6.2)$ & $169.8(5.5)^{*}$ & $165.8(6.2)^{*}$ \\
\hline \multicolumn{5}{|l|}{ Height group $(\mathrm{cm}) \ddagger$} \\
\hline$<164$ & $32(15.2)$ & $52(21.8)$ & $29(12.2)$ & $78(32.9)^{* *}$ \\
\hline $164-167$ & $48(22.7)$ & $44(18.5)$ & $36(15.2)$ & $56(23.6)^{\star *}$ \\
\hline $168-171$ & $73(34.6)$ & $82(34.5)$ & $86(36.3)$ & $61(25.7)^{* *}$ \\
\hline $172+$ & $58(27.5)$ & $60(25.2)$ & $86(36.3)$ & $42(17.7)^{\star *}$ \\
\hline \multicolumn{5}{|l|}{ Smoking status $\ddagger$} \\
\hline Never smoker & $56(26.5)$ & $89(37.4)$ & $57(24.1)$ & $66(27.8)$ \\
\hline Current smoker & $115(54.5)$ & $136(57.1)$ & $172(72.6)^{* *}$ & 151 (63.7) \\
\hline Ex-smoker & $40(19.0)$ & $13(5.5)^{\star *}$ & $8(3.4)^{\star *}$ & $20(8.4)^{\star \star}$ \\
\hline \multicolumn{5}{|l|}{ Cigarette-years of smoking $\ddagger$} \\
\hline 0 & $56(26.5)$ & $89(37.4)$ & $57(24.1)$ & $66(27.8)$ \\
\hline $1-99$ & $68(32.2)$ & $44(18.5)$ & $46(19.4)$ & $52(21.9)$ \\
\hline $100-199$ & $38(18.0)$ & $29(12.2)$ & $27(11.4)$ & $43(18.1)$ \\
\hline $200-299$ & $33(15.6)$ & $24(10.1)$ & $28(11.8)$ & 35 (14.8) \\
\hline $300+$ & $16(7.6)$ & $52(21.8)^{\star *}$ & $79(33.3)^{* *}$ & $41(17.3)^{*}$ \\
\hline $\begin{array}{l}\text { Cumulative BSF exposure level } \\
\left(\mu \mathrm{g} / \mathrm{m}^{3} \text {-years }\right) \dagger \S\end{array}$ & - & $2.6,449.5,505.2$ & $3.0,1147.8,1263.0$ & $3.7,7141.6,4420.5$ \\
\hline \multicolumn{5}{|c|}{$\begin{array}{l}{ }^{*} \mathrm{p}<0.05 ;{ }^{* *} \mathrm{p}<0.01 v \text { control group. } \\
\text { †Geometric mean, arithmetic mean, median. } \\
\text { †Number (\%). } \\
\text { TArithmetic mean (SD). } \\
\S p<0.01 \text { (linear trend test across control group to high exposure group). }\end{array}$} \\
\hline
\end{tabular}

risk associated with COE exposure) or cumulative BSF exposure (when analysing the risk associated with smoking). The adjusted odds ratios (ORs) and 95\% CIs were calculated from these models. Smoking status was divided into five categories of cumulative exposure to tobacco: never smokers (0 cigarette-years) and smokers of 1-99, 100-199, 200-299, and $\geqslant 300$ cigarette-years. The covariate ages were $<30,30-$ $34,35-39$, and $\geqslant 40$ years and the covariate heights were $<164$, 164-167, 168-171, and $\geqslant 172 \mathrm{~cm}$, which were an approximate quartile and the same interval in the second and the third group. The interaction between cumulative $\mathrm{COE}$ exposure and smoking was evaluated by joint classification and a logistic regression model.

\section{RESULTS}

\section{Characteristics of study subjects}

The characteristics of the subjects at the two coking plants and the control group are shown in table l. Compared with the control group, the moderate exposure group had fewer women and was older and taller. The mean height of the high exposure group was lower. There were relatively few

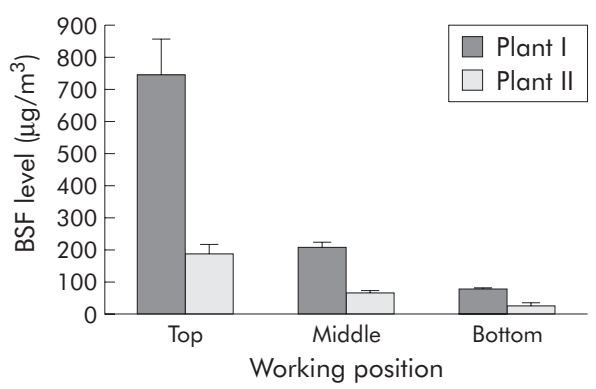

Figure 1 Benzene soluble fraction (BSF) levels of personal air samples at the bottom, middle and top of two coke oven plants. ex-smokers and more heavy smokers ( $\geqslant 300$ cigarette-years) in the exposure groups.

\section{Individual exposure assessment}

Figure 1 shows the BSF levels monitored by person samples at the bottom, middle and top of coke ovens at the two coking plants. The mean BSF level at plant I was higher than that in plant II when corresponding working positions were compared. Workers at the top of the coke oven at plants I and II and at the middle of the oven at plant I were exposed to $743.8 \mu \mathrm{g} / \mathrm{m}^{3}, 190.5 \mu \mathrm{g} / \mathrm{m}^{3}$ and $210.5 \mu \mathrm{g} / \mathrm{m}^{3}$, respectively, which exceeds the OSHA standard $\left(150 \mu \mathrm{g} / \mathrm{m}^{3}\right)$. No BSF was detected in the control group. The cut off points providing three equal groups of cumulative exposure to COE were $630.0 \mu \mathrm{g} / \mathrm{m}^{3}$-years and $1714.0 \mu \mathrm{g} / \mathrm{m}^{3}$-years. The arithmetic means of the cumulative exposure level based on ambient monitoring results and duration of exposure were $449.5,1147.8$, and $7141.6 \mu \mathrm{g} / \mathrm{m}^{3}$-years for workers with low, moderate and high exposure, respectively (table 1 ). The geometric mean individual cumulative COE level was similar in plants I $\left(3.1 \mu \mathrm{g} / \mathrm{m}^{3}\right.$-years $)$ and II $\left(3.0 \mu \mathrm{g} / \mathrm{m}^{3}\right.$-years $)$. As the mean duration of employment at plant I was shorter than at plant II (6 years and 10.5 years, respectively) and the mean BSF level was higher at plant I than at plant II $\left(344.8 \mu \mathrm{g} / \mathrm{m}^{3}\right.$ and $95.8 \mu \mathrm{g} / \mathrm{m}^{3}$, respectively), the patterns of exposure at plants I and II were regarded as short term exposure at higher levels and long term exposure at lower levels, respectively.

\section{Effects of exposure to COE on lung function, respiratory symptoms, and COPD}

$\mathrm{FVC}, \mathrm{FEV}_{1}, \mathrm{FEV}_{1} / \mathrm{FVC}$ and $\mathrm{FEV}_{1} \%$ predicted in coke oven workers decreased significantly with cumulative BSF exposure levels (table 2). The mean FVC, $\mathrm{FEV}_{1}$ and $\mathrm{FEV}_{1} \%$ predicted values were lower in the exposure groups than in the control group, while lower $\mathrm{FEV}_{\mathrm{l}} / \mathrm{FVC}$ values were found 
Table 2 Adjusted mean $(95 \% \mathrm{Cl})$ of lung function indices in control group and exposure groups

\begin{tabular}{|c|c|c|c|c|}
\hline & $\begin{array}{l}\text { Control group } \\
(n=211)\end{array}$ & $\begin{array}{l}\text { Low exposure } \\
(n=238)\end{array}$ & $\begin{array}{l}\text { Moderate exposure } \\
(n=237)\end{array}$ & $\begin{array}{l}\text { High exposure } \\
(\mathrm{n}=237)\end{array}$ \\
\hline FVC (l)†‡ & 5.06 (4.93 to 5.19$)$ & $4.84(4.72 \text { to } 4.96)^{*}$ & $4.73(4.60 \text { to } 4.84)^{* *}$ & $4.74(4.62 \text { to } 4.86)^{* *}$ \\
\hline $\mathrm{FEV}_{1}$ (I)†‡ & $4.27(4.15$ to 4.40$)$ & $4.04(3.92 \text { to } 4.16)^{* *}$ & $3.89(3.76 \text { to } 4.00)^{* *}$ & $3.85(3.73 \text { to } 3.97)^{* *}$ \\
\hline $\mathrm{FEV}_{1} / \mathrm{FVC}(\%) \dagger \ddagger$ & 84.39 (83.00 to 85.77$)$ & 83.23 (81.93 to 84.53$)$ & $82.02(80.70 \text { to } 83.35)^{*}$ & $80.12(78.79 \text { to } 81.44)^{* *}$ \\
\hline $\mathrm{FEV}_{1}(\%$ pred $) \dagger \ddagger$ & $101.60(98.60$ to 104.60$)$ & $95.50(92.68 \text { to } 98.32)^{* *}$ & $92.22(89.34 \text { to } 95.10)^{* *}$ & $92.22(89.44 \text { to } 95.09)^{\text {** }}$ \\
\hline
\end{tabular}

${ }^{*} \mathrm{p}<0.05,{ }^{* *} \mathrm{p}<0.01 v$ control group.

†Mean $(95 \% \mathrm{Cl})$ adjusted for sex, age $(<30,30-34,35-39$, and $\geqslant 40$ years), height $(<164,164-167,168-171$, and $\geqslant 172 \mathrm{~cm})$ and cigarette-years of smoking $(0,1-99,100-199,200-299$ and $\geqslant 300)$.

$\ddagger \mathrm{p}<0.01$, linear trend test across control group to high exposure group.

only in the moderate and high exposure groups. There was a significant dose-response relationship between cumulative BSF exposure level and chronic cough/phlegm or COPD after adjustment for sex, age, height, and cigarette-years of smoking (table 3). The ORs of chronic cough/phlegm and COPD associated with the highest cumulative BSF exposure $\left(\geqslant 1714.0 \mu \mathrm{g} / \mathrm{m}^{3}\right.$-years) were 3.10 (95\% CI 1.91 to 5.03$)$ and 5.80 (95\% CI 3.13 to 10.76), respectively. Only COPD of moderate severity was related to cumulative BSF exposure level (table 3).

A separate analysis for each coking plant also found that there was a significant dose-dependent increase in the risk of COPD in each plant, although the slope calculated from the linear portions of cumulative BSF exposure-response curves was slightly different between plants I and II (1.13 and 1.46, respectively). Significantly lower lung function and a higher risk of COPD was seen in coke oven workers at plant II $\quad\left(\mathrm{FVC}=4.65 \mathrm{l}, \mathrm{FEV}_{1}=3.83 \mathrm{l}, \mathrm{FEV}_{1} / \mathrm{FVC}=81.75 \%\right.$, $\mathrm{FEV}_{1}=90.93 \%$ predicted, COPD risk: $\mathrm{OR}=3.39(95 \%$ CI 1.88 to 6.10) $)$ than in those at plant $\mathrm{I}\left(\mathrm{FVC}=4.94 \mathrm{l}, \mathrm{FEV}_{\mathrm{l}}=4.06 \mathrm{l}\right.$, $\mathrm{FEV}_{1} / \mathrm{FVC}=81.84 \%, \mathrm{FEV}_{1}=96.83 \%$ predicted, COPD risk: $\mathrm{OR}=3.17$ (95\% CI 1.68 to 5.96$)$ ) after adjusting for sex, age, height, and cigarette-years of smoking.

\section{Relationship between cumulative cigarette smoking, respiratory symptoms and COPD}

Chronic cough/chronic phlegm and COPD were significantly influenced by cumulative cigarette smoking after adjusting for sex, age, height, and cumulative BSF exposure (table 4). Heavy smokers ( $\geqslant 300$ cigarette-years) had a 1.93-fold risk for chronic cough/phlegm (95\% CI 1.19 to 3.13) and a 5.26fold risk for COPD (95\% CI 2.90 to 9.53). Only the prevalence of moderate COPD increased with cigarette-years of smoking (table 4). A dose-response relationship between cigarette-years of smoking and chronic cough/phlegm or COPD was also found among coke oven workers at each coking plant. The slopes for chronic cough/phlegm in plants I and II were similar ( 0.78 and 0.70 , respectively), but the slopes for COPD were significantly different between plants I and II (0.88 and 2.67, respectively).

\section{Interaction between cumulative BSF exposure and cigarette smoking in COPD}

Table 5 shows the risk of COPD for combinations of cumulative BSF exposure and cigarette-years of smoking. Cumulative BSF exposure was associated with an increased risk of COPD for both smokers of different duration and never smokers. The results from the two coking plants showed a degree of consistency. The interaction between cumulative BSF exposure and cigarette smoking was statistically significant $(\mathrm{p}<0.01$ for both plants $)$.

\section{DISCUSSION}

Recent research has found that some occupational factors may be driving outcomes in COPD..$^{3-6}$ However, there have been only limited studies of the association between COE exposure and COPD. The present study quantitatively estimated individual cumulative $\mathrm{COE}$ exposure as well as cigarette smoking and investigated the risk of COPD. Decreased FVC, $\mathrm{FEV}_{1}$ and $\mathrm{FEV}_{1} \%$ predicted were found with low levels of COE exposure $\left(<630.0 \mu \mathrm{g} / \mathrm{m}^{3}\right.$-years $)$ while reduced $\mathrm{FEV}_{1} / \mathrm{FVC}$ was found with moderate COE exposure ( $\geqslant 630.0 \mu \mathrm{g} / \mathrm{m}^{3}$-years). The dose-dependent changes in lung function parameters, particularly $\mathrm{FEV}_{\mathrm{l}} / \mathrm{FVC}$, were consistent with the increased risk of COPD. This association suggests that the effect on lung function could be a useful predictor of COPD to evaluate the risk of COPD in coke oven workers. In addition, a significant dose-response relationship was found

Table 3 Adjusted odds ratios $(95 \% \mathrm{Cl})$ of respiratory symptoms and COPD associated with COE exposure using control group as a referent

\begin{tabular}{|c|c|c|c|c|}
\hline & $\begin{array}{l}\text { Control group } \\
(n=211)\end{array}$ & $\begin{array}{l}\text { Low exposure } \\
(n=238)\end{array}$ & $\begin{array}{l}\text { Moderate exposure } \\
(n=237)\end{array}$ & $\begin{array}{l}\text { High exposure } \\
(n=237)\end{array}$ \\
\hline \multicolumn{5}{|l|}{ Number and prevalence ${ }^{*}$} \\
\hline Chronic cough or chronic phlegm & 29 (13.7) & $50(21.0)$ & $62(26.2)$ & $82(34.6)$ \\
\hline COPD & $15(7.1)$ & $29(12.2)$ & $56(23.6)$ & $71(30.0)$ \\
\hline Mild & $4(1.9)$ & $7(2.9)$ & $5(2.1)$ & $3(1.3)$ \\
\hline Moderate & $8(3.8)$ & $18(7.6)$ & $41(17.3)$ & $58(24.5)$ \\
\hline Severe & $3(1.4)$ & $3(1.3)$ & $10(4.2)$ & $9(3.8)$ \\
\hline Very severe & $0(0.0)$ & $1(0.4)$ & $0(0.0)$ & $1(0.4)$ \\
\hline \multicolumn{5}{|l|}{ Adjusted OR (95\% Cl)† } \\
\hline Chronic cough or chronic phlegm & 1 (referent) & $1.60(0.97$ to 2.65$)$ & $1.99(1.21$ to 3.26$)$ & 3.10 (1.91 to 5.03$)$ \\
\hline COPD & 1 (referent) & $1.68(0.86$ to 3.27$)$ & 3.21 (1.71 to 6.01$)$ & 5.80 (3.13 to 10.76$)$ \\
\hline Mild & 1 (referent) & $1.74(0.49$ to 6.20$)$ & $1.27(0.31$ to 5.14$)$ & $0.77(0.16$ to 3.60$)$ \\
\hline Moderate & 1 (referent) & $1.89(0.80$ to 4.47$)$ & $4.00(1.80$ to 8.89$)$ & 8.22 (3.76 to 17.97 ) \\
\hline Severe or very severe & 1 (referent) & $1.03(0.22$ to 4.80$)$ & $2.26(0.57$ to 8.93$)$ & 2.75 (0.71 to 10.66$)$ \\
\hline
\end{tabular}


Table 4 Adjusted ORs of respiratory symptoms and COPD associated with cigarette smoking

\begin{tabular}{|c|c|c|c|c|c|}
\hline & \multicolumn{5}{|c|}{ Cigarette-years of smoking } \\
\hline & $\begin{array}{l}\text { Never } \\
(n=268)\end{array}$ & $\begin{array}{l}1-99 \\
(n=210)\end{array}$ & $\begin{array}{l}100-199 \\
(n=137)\end{array}$ & $\begin{array}{l}200-299 \\
(n=120)\end{array}$ & $\begin{array}{l}\geqslant 300 \\
(n=188)\end{array}$ \\
\hline \multicolumn{6}{|l|}{ Number and prevalence ${ }^{*}$} \\
\hline Chronic cough or chronic phlegm & $57(21.3)$ & $36(17.1)$ & $29(21.2)$ & $37(30.8)$ & $64(34.0)$ \\
\hline COPD & $25(9.3)$ & $24(11.4)$ & $26(19.0)$ & $29(24.2)$ & $67(35.6)$ \\
\hline Mild & $5(1.9)$ & $3(1.4)$ & $4(2.9)$ & $1(0.8)$ & $6(3.2)$ \\
\hline Moderate & $18(6.7)$ & $21(10.0)$ & $14(10.2)$ & $24(20.0)$ & $48(25.5)$ \\
\hline Severe & $2(0.7)$ & $0(0.0)$ & $8(5.8)$ & $4(3.3)$ & $11(5.9)$ \\
\hline Very severe & $0(0.0)$ & $0(0.0)$ & $0(0.0)$ & $0(10.0)$ & $2(1.1)$ \\
\hline \multicolumn{6}{|l|}{ Adjusted OR $(95 \% \mathrm{Cl}) \dagger$} \\
\hline Chronic cough or chronic phlegm & 1 (referent) & $0.77(0.48$ to 1.24$)$ & $0.99(0.58$ to 1.66$)$ & 1.73 (1.03 to 2.91$)$ & 1.93 (1.19 to 3.13$)$ \\
\hline COPD & 1 (referent) & $1.46(0.78$ to 2.72$)$ & $2.40(1.28$ to 4.51$)$ & 3.25 (1.72 to 6.15$)$ & 5.26 (2.90 to 9.53$)$ \\
\hline Mild & 1 (referent) & $1.23(0.27$ to 5.67$)$ & 2.23 (0.53 to 9.37$)$ & $0.48(0.05$ to 4.52$)$ & $2.25(0.52$ to 9.67$)$ \\
\hline Moderate & 1 (referent) & $1.59(0.80$ to 3.16$)$ & $1.43(0.67$ to 3.05$)$ & $3.28(1.62$ to 6.64$)$ & $4.16(2.14$ to 8.09$)$ \\
\hline Severe or very severe & 1 (referent) & - & 10.47 (1.99 to 55.04$)$ & $5.72(0.92$ to 35.49$)$ & $11.92(2.14$ to 66.31$)$ \\
\hline \multicolumn{6}{|c|}{$\begin{array}{l}\text { *Number (\%). } \\
\text { †Adjusted for sex, age }(<30,30-34,35-39 \text {, and } \geqslant 40 \text { years), height }(<164,164-167,168-171 \text {, and } \geqslant 172 \mathrm{~cm}) \text {, and cumulative COE exposure levels }(0 \text {, } \\
<630,630-1713 \text {, and } \geqslant 1714 \mu \mathrm{g} / \mathrm{m}^{3} \text {-years) by logistic regression. }\end{array}$} \\
\hline
\end{tabular}

between COE exposure and the risk of chronic respiratory symptoms (chronic cough/phlegm) or COPD after controlling for potential confounding factors such as sex, age, height, and cigarette smoking. Similar effects of life-time cigarette smoking on respiratory symptoms and COPD were also found by non-conditional logistic analysis. Neither COE exposure nor cigarette smoking was strongly influenced by COPD severity, except for moderate COPD. This suggests that prolonged and repetitive exposure to cigarette smoking or COE could stimulate the respiratory airway and induce bronchial inflammation, which might lead to the development of COPD.

The most important finding in this study is the synergistic effect of COE exposure and cigarette smoking in the development of COPD when the data from the two coking plants were analysed separately or together. The risk of COPD in subjects with the highest cumulative exposure to cigarette smoking and COE was 58-fold compared with non-smokers with no exposure to COE.

There are several possible explanations for this synergistic activity. Some components of COE and cigarette smoking (irritant gases and particulates) could directly irritate the airways and induce chronic inflammation of the lung parenchyma and airways involved in the initiation and progression of COPD. Cigarette smoking increases the uptake and retention of particles by alveolar epithelial cells ${ }^{19}$ which may enhance the inflammatory effects of COE on the lung. Cigarette smoke contains a large amount of reactive oxygen species (ROS). ${ }^{20}$ In addition, some constituents of cigarette smoke may also release iron from ferritin, potentiating oxidative stress. $^{21}$ Besides these direct mechanisms of increased oxidative stress, cigarette smoking also enhances oxidative stress by recruiting and activating phagocytes to release ROS.22 The increased levels of ROS probably activate PAHs as the main component of COE to form highly toxic metabolites ${ }^{23}$ which could contribute to the development of COPD. Further experimental work is needed to elucidate the apparent synergy between COE exposure and cigarette smoking.

The observed association between occupational COE exposure or smoking and COPD and the interaction between COE exposure and smoking were found at both coking plants. Although there was a similar cumulative exposure level in coke oven workers at the two plants, the patterns of exposure were different in plants I and II. Furthermore, individuals at plant II (long term exposure at lower levels) had a higher risk of COPD than those at plant I (short term exposure at higher levels), suggesting that the different patterns of exposure and/or genetic factors may contribute to the development of COPD.

The "healthy work effect" has been found in many cross sectional studies. Healthy workers may remain at work while "ill" workers tend to leave or change occupations. In the present study, this seems less likely because a large surplus workforce in China requires workers to continue to work even if they have respiratory complaints or severe COPD. Approximately $95 \%$ and $90 \%$ of all workers in the control and exposure groups, respectively, participated in the project. A significant selection bias in subject recruitment is therefore unlikely. Although the participation rate for coke oven workers was somewhat lower than for controls, this rate does not necessarily limit our inferences from the study as long as the participating coke oven workers reflect the exposure distribution of the source population of the cases. In this study there was a similar distribution of cumulative COE exposure in both participating coke oven workers and those who refused to participate.

The prevalence of COPD varies in different general populations in China. Chen et $a l^{24}$ conducted a survey in subjects aged over 15 years in three regions of China

Table 5 Adjustedt ORs (with $95 \% \mathrm{Cl}$ ) of COPD associated with cumulative COE exposure and smoking

\begin{tabular}{|c|c|c|c|c|c|}
\hline & \multicolumn{5}{|c|}{ Cigarette-years of smoking } \\
\hline & 0 & $1-99$ & $100-199$ & 200-299 & $\geqslant 300$ \\
\hline Control & 1 (referent) & $2.28(0.31$ to 16.56$)$ & $2.65(0.41$ to 17.26$)$ & $2.22(0.33$ to 14.82$)$ & 7.51 (1.11 to 50.89$)$ \\
\hline Low exposure & $2.77(0.54$ to 14.33$)$ & $3.62(0.59$ to 22.26$)$ & 4.39 (0.63 to 30.62$)$ & 5.35 (0.76 to 37.65$)$ & $11.08(2.11$ to 58.11$)$ \\
\hline Moderate exposure & $3.98(0.75$ to 21.24$)$ & 5.68 (0.98 to 32.89$)$ & $15.92(2.80$ to 90.60$)$ & 17.58 (3.13 to 98.78$)$ & 19.05 (3.81 to 95.31$)$ \\
\hline High exposure & $5.92(1.20$ to 29.32$)$ & 10.53 (2.02 to 54.90$)$ & 14.75 (2.84 to 76.68$)$ & 27.13 (5.09 to 144.69$)$ & 58.12 (11.07 to 305.12$)$ \\
\hline
\end{tabular}


(northern: Beijing; north-east: Liao-Ning; and south-mid: HuBei) and found the prevalence of COPD to be 3\%. Liu et $a l^{25}$ found the prevalence of COPD in those aged over 40 years was $9.4 \%$ in Guangdong (south-east). Our results for the control group $(7.0 \%)$ were similar to those reported in a Chinese population aged 30 years and over by the Asian Pacific Society of Respiratory Diseases (6.5\%). ${ }^{26}$ In addition, ethnic background, life styles, and dietary patterns were similar in the control group and exposure groups in our study. COPD was defined according to GOLD criteria. Although there were differences in sex, age, height, and cigarette smoking, these factors were adjusted for in the regression analysis. The selection of the control group cannot therefore lead to an underestimation or overestimation of the risk of COPD.

Individual early exposure levels were not available in the study. Individual cumulative COE exposure was estimated based on the current measured levels and the period of employment in the working position. However, no improvements in engineering technology or in the production capacity per year of coke ovens occurred in the two plants investigated, so the level of COE exposure at representative working positions was assumed to be relatively constant. The mean levels of COE exposure at the top of the coke oven at plants I and II and in the middle of the coke oven in plant I were about 5.0, 1.3, and 1.4 times the OSHA permissible exposure limit for COE, respectively. The top and middle of coke ovens appear to be important pollutant areas. Since a significant dose-response relationship between cumulative COE exposure and COPD was found and cigarette smoking had a modifying effect, improvements in the technology of coke oven production are needed to reduce the levels of COE exposure and employment periods in those areas. Meanwhile, smoking cessation, personal protection in the work place, and routine health surveillance for coke oven workers should be emphasised.

It is possible that smoking histories could be inaccurately recalled, especially smoking which occurred several years earlier, so the information on smoking included in the record of pre-employment and periodic medical examination for workers (annual or biannual) was checked to minimise the recall error. An additional concern might be a cohort effect among older subjects with higher levels of cumulative COE exposure and tobacco consumption who could have had a less satisfactory indoor environment or poor nutritional conditions in childhood. However, analysis of the preemployment medical examination records showed that older subjects lived in families with slightly higher incomes than other workers, for which there is no reasonable explanation, so it is difficult to conclude that older subjects lived in poor domestic environments in childhood.

In conclusion, this study has shown that exposure to COE enhances the risk for respiratory symptoms and COPD with a significant dose-response relationship. A synergistic effect of COE exposure and cigarette smoking on the risk of COPD was found. Appropriate public health interventions-for example, the reduction of COE concentrations in the workplace and cigarette smoking cessation programmes-are needed. In addition, medical surveillance including lung function testing should be part of a preventive programme. Large numbers of additional cases of COPD can be prevented by focusing on populations exposed to COE.

\section{ACKNOWLEDGEMENTS}

The authors thank Dr Jusheng Pan, Anti-epidemic and Prevention Station of Jiangxi Xinyu Iron-Steel Company and Dr Xiong Sun, Shanghai Coke Oven Company for their kind assistance.

\section{Authors' affiliations}

Y Hu, B Chen, Z Yin, L Jia, Y Zhou, T Jin, Department of Environmental and Occupational Health, Fudan University, Shanghai 200032,

P R China

Y Hu, National Research Council, Washington, DC 20001, USA

This study was supported by "973" project from National Department of Science and Technology, P R China (2002CB512902).

Competing interests: none declared.

\section{REFERENCES}

1 World Health Organization. World health report 2000, Health systems: improving performance. Annex table 3. Geneva: World Health Organization, 2000.

2 Anto JM, Vermeire P, Vestbo J. Epidemiology of chronic obstructive pulmonary disease. Eur Respir J 2001;17:982-94.

3 Seixas NS, Robins TG, Attfield MD, et al. Exposure-response relationships for coal mine dust and obstructive lung disease following enactment of the Federal Coal Mine Health and Safety Act of 1969. Am J Ind Med 1992;21:715-34.

4 Isidro Montes I, Rego Fernandez G, Reguero J, et al. Respiratory disease in a cohort of 2579 coal miners followed up over a 20 -year period. Chest 2004; 126:622-9.

5 Ulvestad B, Bakke B, Melbostad E, et al. Increased risk of obstructive pulmonary disease in tunnel workers. Thorax 2000;55:277-82.

6 Meijer E, Kromhoult H, Heederik D. Respiratory effects of exposure to low levels of concrete dust containing crystalline silica. Am J Ind Med 2001;40:133-40.

7 Trupin L, Earnest G, San Pedro M, et al. The occupational burden of chronic obstructive pulmonary disease. Eur Respir J 2003;22:462-9.

8 International Agency for Research on Cancer (IARC). IARC monographs on the evaluation of carcinogenic risk of chemicals to humans polynuclear armotic compounds. Lyon, France: IARC, 1984:101-31.

9 Xu Z, Brown LM, Pan GW, et al. Cancer risks among iron and steel workers in Anshan, China, Part II: Case-control studies of lung and stomach cancer. Am J Ind Med 1996;30:7-15.

10 Costantino JP, Redmond CK, Bearden A. Occupationally related cancer risk among coke oven workers: 30 years of follow-up. J Occup Environ Med 1995;37:597-604.

11 Wu J, Kreis IA, Griffiths D, et al. Respiratory symptoms and lung function of coke oven workers: a lung function surveillance system from 1990-2000. J Occup Environ Med, 2004;46:906-15.

12 Wu J, Kreis IA, Griffiths D, et al. Cross sectional study on lung function of coke oven workers: a lung function surveillance system from 1978 to 1990. Occup Environ Med 2002;59:816-23.

13 Corhay JL, Bury T, Louis R, et al. Bronchial responsiveness in active steelworkers. Eur Respir J 1998;11:272-7.

14 National Institute for Occupational Safety, Health (NIOSH). Pocket guide to chemical hazards. Cincinnati: US Department of Health and Human Services, Public Health Service, Centers for Disease Control and Prevention, 2002.

15 Lwanga SK, Lemeshow S. Sample size determination in health studies. Geneva: World Health Organization, 1991:35

16 Occupational Safety, Health Administration (OSHA). Method No 58. In:OSHA Analytical Methods Mannual, Volume 3. Salt Lake City: OSHA Analytical Laboratory, 1986:1-41.

17 American Thoracic Society. Standardization of spirometry: 1987 update. Am Rev Respir Dis 1987;136:195-202.

18 National Institute of Health, National Heart Lung and Blood Institute (NHLBI). Global strategy for the diagnosis, management, and prevention of chronic obstructive pulmonary disease, Based on April 1998 NHLBI/WHO Workshop, April 2001 (updated 2003)..

19 Churg A. Interactions of exogenous or evoked agents and particles: the role of reactive oxygen species. Free Radic Biol Med 2003;34:1230-5.

20 Church DF, Pryor WA. Free-radical chemistry of cigarette smoke and its toxicological implications. Environ Health Perspect 1985;64:111-26.

21 Moreno JJ, Foroozesh M, Church DF, et al. Release of iron from ferritin by aqueous extracts of cigarette smoke. Chem Res Toxicol 1992;5:116-23.

22 Ludwig PW, Hoidal JR. Alterations in leukocyte oxidative metabolism in cigarette smokers. Am Rev Respir Dis 1992;126:977-80.

23 Park JH, Gopishetty S, Szewczuk LM, et al. Formation of 8-oxo-7,8-dihydro2'-deoxyguanosine (8-oxo-dGuo) by PAH o-quinones: involvement of reactive oxygen species and copper (II)/copper (I) redox cycling. Chem Res Toxicol 2005; 18:1026-37.

24 Chen XS. Analysis of basic data of the study on prevention and treatment of COPD. Chin J Tuberc Respir Dis 1998;21:749-52.

25 Liu SM, Wang XP, Wang DL, et al. Epidemiologic analysis of COPD in Guangdong province. Chin J Med 2005;85:747-52.

26 Regional COPD Working Group. COPD prevalence in 12 Asian Pacific countries and regions: projections based on the COPD prevalence estimation model. Respirology 2003;8:192-8. 